\title{
Ductility and internal forces redistribution in lightweight aggregate concrete beams
}

\author{
Tomasz Waśniewski ${ }^{1}$, Ewelina Kołodziejczyk ${ }^{2}$ \\ ${ }^{1}$ Department of Concrete Structures; Faculty of Civil Engineering, Architecture and Environmental \\ Engineering; Lodz University of Technology; 6 Politechniki Avenue, 90-924 Lodz, Poland; \\ tomasz.wasniewski@p.lodz.pl (D) 0000-0001-7303-4920 \\ ${ }^{2}$ Department of Concrete Structures; Faculty of Civil Engineering, Architecture and Environmental \\ Engineering; Lodz University of Technology; 6 Politechniki Avenue, 90-924 Lodz, Poland; \\ ewelina.kolodziejczyk@p.lodz.pl (iD)0000-0002-3533-4145
}

\begin{abstract}
Lightweight Aggregate Concrete (LWAC) is typically defined as concrete having a density smaller than or equal to $2200 \mathrm{~kg} / \mathrm{m}^{3}$ and can be obtained by mixing natural or artificial lightweight aggregates. There is a general scepticism regarding the use of lightweight aggregate concrete (LWAC) for structural applications. This concern is attached to the more brittle material behaviour which leads to lower ductility.

This article presents a numerical parametric analysis of the behaviour of the reinforced LWAC cross-sections under the immediate load taking into account the density of the LWAC concrete, concrete strength and tensile reinforcement ratio.

Numerical analysis of the beams was conducted in OpenSees, an open-source nonlinear finite element method framework. One-dimensional elements, with three degrees of freedom at each end, were used. Bending stiffness in the integration points was calculated based on the sectional moment - curvature relationship.

The analysis showed that there is a relationship between the ductility of the cross-sections made of lightweight concrete and its density class. It is associated with limited compressive strains and the brittle behavior of LWAC. The limited rotation capacity of the reinforced concrete sections made of LWAC also affects the ability of redistribution of internal forces in statically indeterminate beams.
\end{abstract}

Keywords: lightweight, concrete, ductility, redistribution, beams 


\section{Introduction}

The ductility of the reinforced concrete elements can be defined as the ability to plastic deformation, in the area of permissible loads and also above it. High ductility means that the structure can transfer loads despite the overloading of its critical sections. Admittedly, excessive displacements and deflections may occur, but the load capacity of the structure will be maintained. In the statically indeterminate systems, adequate ductility ensures the ability to rotate of critical cross-sections, which allows the proper redistribution of the internal forces.

Lightweight Aggregate Concrete (LWAC) is typically defined as concrete, having a density smaller than or equal to $2200 \mathrm{~kg} / \mathrm{m}^{3}$ and can be obtained by mixing natural or artificial lightweight aggregates [1]. There is a general scepticism regarding the use of lightweight aggregate concrete (LWAC) for structural applications. This concern is attached to the more brittle material behaviour, which leads to lower ductility [2]-[5].

This article presents a numerical parametric analysis of the behaviour of the reinforced LWAC cross-sections under the immediate load taking into account the density of the LWAC concrete, concrete strength and tensile reinforcement ratio.

Numerical analysis of the deformations and internal forces redistribution of the doublespan beams made of LWAC and reinforced with different reinforcement ratio is presented. The moment-curvature relationship is used as a constitutive sectional law.

\section{Material characteristics and ultimate strains in LWAC}

Lightweight aggregate concrete is classified according to its density into six classes [1]. For each class and compressive strength, the material parameters such as modulus of elasticity or ultimate compressive strains are obtained from parameters of the corresponding normal weight concrete by multiplying them by coefficient:

$$
\eta_{E}=\left(\frac{\rho}{2200}\right)^{2}
$$

where:

$\rho-$ is the oven-dry density for the relevant class of the LWAC.

This approach results in a very large diversity of ultimate compressive strains. In figure 1, a general relationship between ultimate compressive strains, compressive strength and density of the lightweight concrete is presented. The value of the ultimate strain extends from the lowest value $\varepsilon_{\text {lcu }}=1.13 \%$ for $f_{\mathrm{lc}}=20 \mathrm{MPa}$ and $\rho=2000 \mathrm{~kg} / \mathrm{m}^{3}$ up to the highest value $\varepsilon_{\mathrm{lcu}}=10.7 \%$ o for $f_{\mathrm{lc}}=80 \mathrm{MPa}$ and $\rho=1000 \mathrm{~kg} / \mathrm{m}^{3}$.

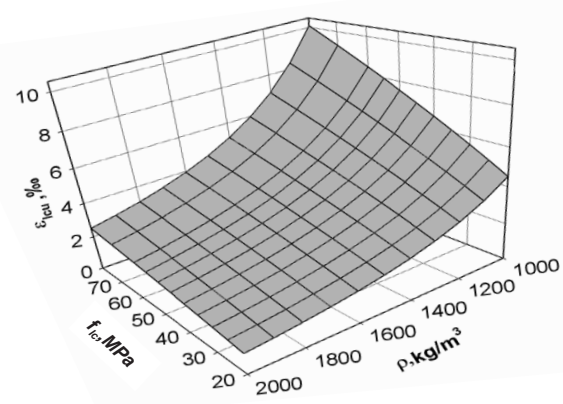

Fig. 1. Relationship between $\varepsilon_{\mathrm{lcu}}-f_{\mathrm{lc}}-\rho$ for LWAC according to [1]. Source: own study 
Figure 2 presents sigma - epsilon characteristics determined according to [1] for lightweight concrete with compressive strength $f_{\mathrm{c}}=30 \mathrm{MPa}$ and $80 \mathrm{MPa}$. Six density classes are included. As can be observed, for both classes, as the density increases, the modulus of elasticity of lightweight aggregate concrete increases, and in all cases material characteristic is almost linear. This type of material behaviour is confirmed in several tests for different aggregates [6]. Compared to normal-weight concrete, lightweight concrete characteristic has a very steep post-peak, softening branch. For this reason, [1] requires the rejection of this part of the characteristic and assumes the strains at maximum stress are equal to the ultimate. This is similar to the behaviour of the higher strength classes of ordinary concrete.

It should be said that part of the combination of compressive strength and density of lightweight concrete, although possible to take into account according to [1], is not possible to obtain using available aggregates. However, [1] does not introduce any restrictions.
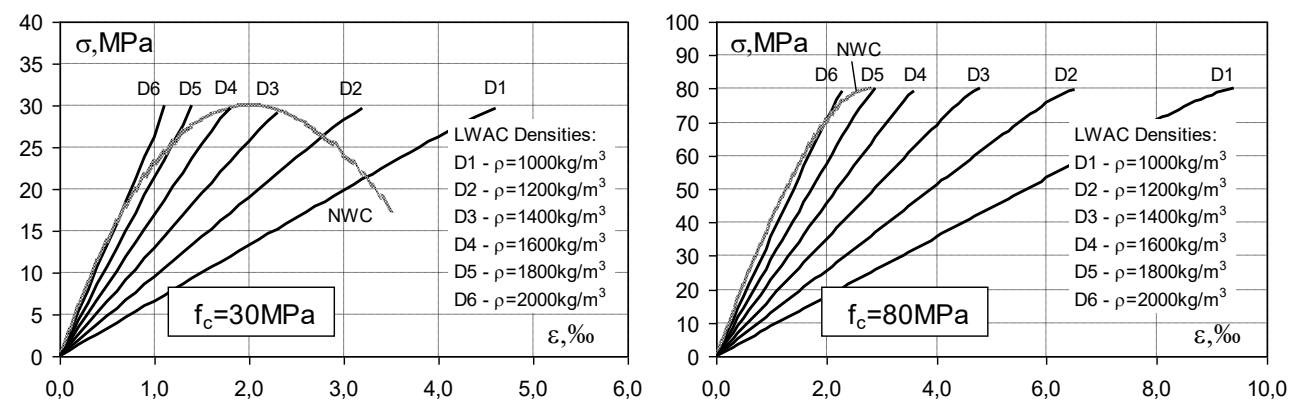

Fig. 2. Sigma - epsilon characteristics of LWAC concrete for two selected strength classes and densities. Source: own study

\section{Ductility index}

Generally, according to conventional methods of determining the ductility index, it is a function of the ultimate deformability of the concrete and the plasticity of the reinforcing steel. In practical applications, two of the most popular approaches to determining this index can be distinguished.

The first method of determining the ductility index is based on a comparison of strains or displacements corresponding to the ultimate moment $M_{\mathrm{u}}$, and the values of these strains or displacements determined at the yielding point of the tensile reinforcement.

The second method of determining the ductility index, proposed in [7], is based on comparing the total energy needed to deform an element or cross-section to the elastic part of this energy.

In this case, the ductility index can be expressed by the following equation:

$$
\mu_{n}=0,5\left(\frac{E_{\text {tot }}}{E_{\text {ela }}}+1\right)
$$

where:

$E_{\text {tot }}$ - total energy needed for deformation, defined as the area under the graph of the force - displacement or moment - curvature relationship up to the ultimate force or moment,

$E_{\text {ela }}$ - elastic energy determined as the area of the triangle created at the point of ultimate force or moment by a straight line; the slope of this line can be determined from the data when the element is unloaded, or from the formula: 


$$
S=\frac{F_{c r} S_{1}+\left(F_{y}-F_{c r}\right) S_{2}}{F_{y}}
$$

In figure 3, a graphic interpretation of this method is presented. If the reinforcement is not plasticized in the above formula, $F_{\mathrm{u}}$ can be substituted for $F_{\mathrm{y}}$. This method allows determining the ductility index both in elements reinforced with elastic-plastic materials and reinforced materials with purely elastic characteristics, e.g. composites.

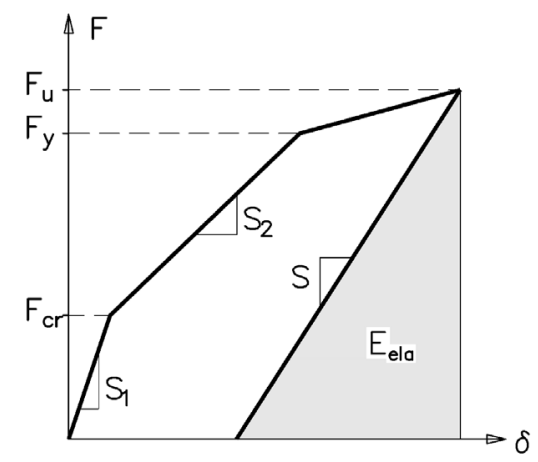

Fig. 3. Graphical interpretation of the ductility index determination according to [7]. Source: [7]

Later in this article, ductility indexes will be determined using the energy method.

\section{Nonlinear analysis of the cross-sections}

\subsection{Basic assumptions}

Parametric nonlinear analysis of the reinforced cross-sections behaviour and their ductility was performed, taking into account the following parameters:

- tensile reinforcement ratio,

- compressive strength and its ultimate compressive strains,

- density of the concrete.

\subsection{Calculation assumptions}

In this study, the layered model of the reinforced section is presented according to [8]. This way of calculation gives good compatibility of the calculations and test results.

This method assumes the following assumptions:

- only normal stress is considered,

- the load is monotonic, singular and irreversible,

- principle of maintaining a flat cross-section is valid throughout the entire load range,

- material relationships of concrete and reinforcing steel were obtained in the uniaxial state of stresses,

- strains of the reinforcement and surrounding concrete are the same,

- non-linear stress - strain characteristic of the compressed normal and lightweight aggregate concrete is used according to [1], 
- principle of tension stiffening is valid; the model is adopted according to [8],

- stress-strain relationship of tensile reinforcing steel is used according to [9],

- in sections with top reinforcement a compressed steel bars model was used according to $[10]$.

The moment - strain or moment - curvature relationships are determined by considering subsequent levels of strain in the cross-section and obtaining by the iteration the internal forces (normal force and bending moment), which are in balance to external forces in section.

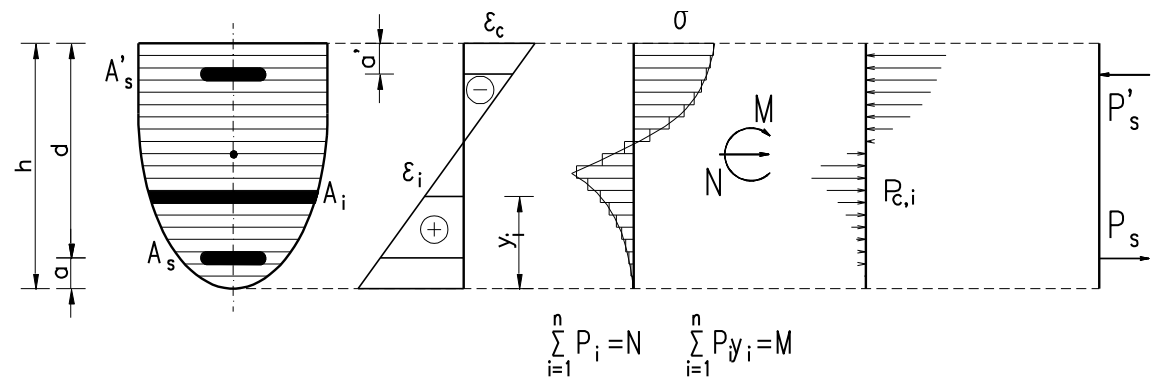

Fig. 4. Discretization of the section and strains and stress state in the layers

The considered cross-section is divided into layers. In figure 4, the discretization of the section and example of strain and stress states in the layers are presented.

Reinforcement bars are treated as a separate layer (or several layers) of known location and cross-sectional area.

\subsection{Results of the calculations}

Figure 5 shows the calculated relative $M$ - $\kappa$ relationships for section reinforced with low tensile reinforcement ratio $\left(\rho_{\mathrm{s}}=0.01\right)$, made of LWAC with different densities. The compressive strength of the concrete is $f_{\mathrm{lc}}=30 \mathrm{MPa}$. For comparison results for normal -weight concrete are also presented.

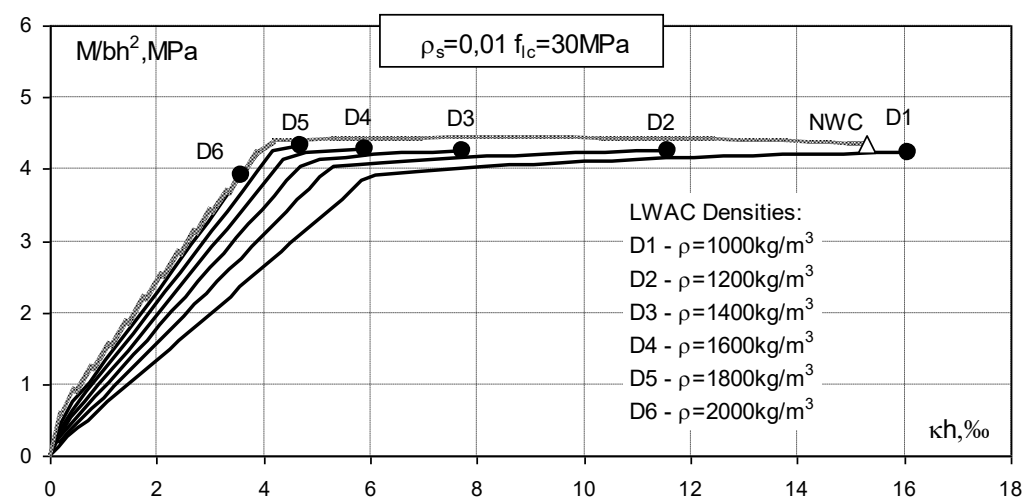

Fig. 5. Moment - curvature relationships for section reinforced with $\rho_{\mathrm{s}}=0.01$. Source: own study

As you can see, in all cases, before the yielding of the reinforcement steel, the impact of a decreasing elastic modulus along with a decrease in the density of concrete is visible. 
After the steel yielding, a strong influence of the ultimate compressive strain of the concrete on the ability to plastic deformation of the cross-section is revealed. For concretes with the highest density, the plastic branch is very short, unlike the concretes with the lowest density, where the plastic branch is clearly longer. The length of the plastic branch directly affects the ductility of the section. It can be seen that for the highest density class $\left(\rho_{\mathrm{s}}=2000 \mathrm{~kg} / \mathrm{m}^{2}\right)$, reinforcement is not yielding at all, and the cross-section loses any ductility.

Interestingly, compared to normal concrete, the closest cross-sectional behaviour was obtained for lightweight concrete with the lowest density class.

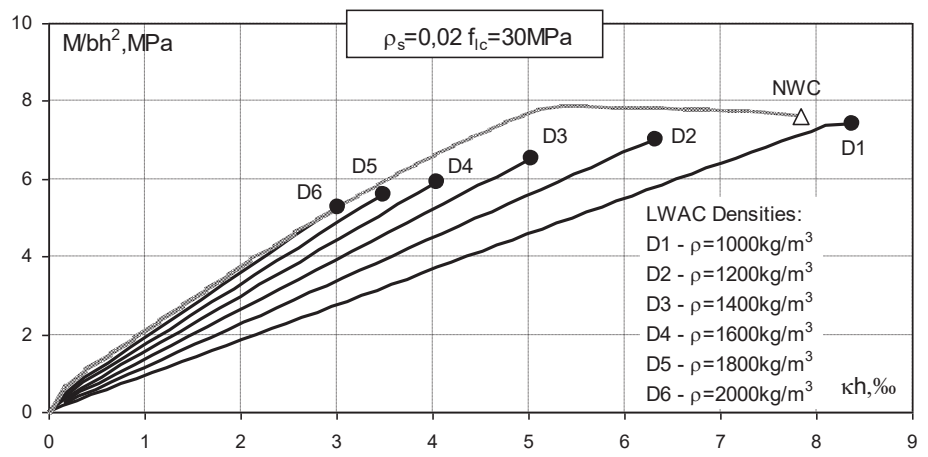

Fig. 6. Moment - curvature relationships for section reinforced with $\rho_{\mathrm{s}}=0.02$. Source: own study

The impact of the limited ultimate strains is even more visible in the case of sections with a higher reinforcement ratio. Figure 6 shows the calculation for the section reinforced with $\rho_{\mathrm{s}}=0.02$. For concrete with a density above $1200 \mathrm{~kg} / \mathrm{m}^{3}$, the reinforcement does not yield, and the cross-section loses its ability to plastic deformation. Meanwhile, normal-weight concrete with the same reinforcement ratio still shows good ductility.

Figure 7 shows the general relationship between the ductility index and the density of concrete for two lightweight concrete compressive strengths. Calculations were carried out for several degrees of reinforcement.
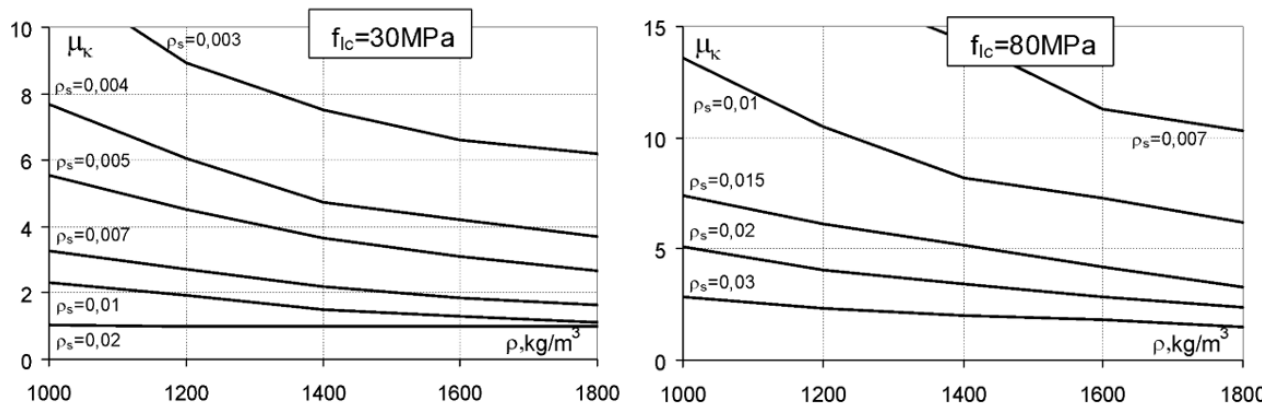

Fig. 7. The general relationship between ductility index and density for two LWAC strength. Source: own study

In both cases, a strong dependence of the ductility index on the density of lightweight aggregate concrete is revealed. The lower the density class, the higher the ductility. This relationship is more visible for cross-sections with a lower tensile reinforcement ratio. 
In the case of concrete with compressive strength $f_{\mathrm{lc}}=30 \mathrm{MPa}$, in more heavily reinforced cross-sections, where tensile reinforcement is higher than 0.01 , the ductility index is very low. This is because the reinforcement does not yield, even if the ultimate compressive strains are greater than in normal-weight concrete. In the cross - sections made of concrete with increased compressive strength $\left(f_{\mathrm{lc}}=80 \mathrm{MPa}\right)$, cross-sections lose their plasticity at higher levels of the reinforcement ratio. $\left(\rho_{\mathrm{s}}>0.03\right)$.

\section{Internal forces redistribution in the double-span beams}

If in any cross-section of the statically indeterminate element or system, the bending moment values are not constantly proportional to the loads at every step load, it means that the rearrangement of internal forces or the redistribution of the bending moments occurs. In the reinforced concrete structures, the main reason for the redistribution of internal forces is the increasing change in stiffness due to cracking and reinforcement yielding.

In [1], the coefficient of redistribution, $\delta$, is defined by eq. (3), and the degree of moment redistribution, $\eta$ (in \%), is defined by eq. (4):

$$
\begin{aligned}
\delta & =\frac{M_{\text {red }}}{M_{\text {elast }}} \\
\eta & =(1-\delta) \cdot 100
\end{aligned}
$$

where $M_{\text {red }}$ is the moment in the support or span section after redistribution, and $M_{\text {elast }}$ is the moment in the same section calculated according to the theory of elasticity.
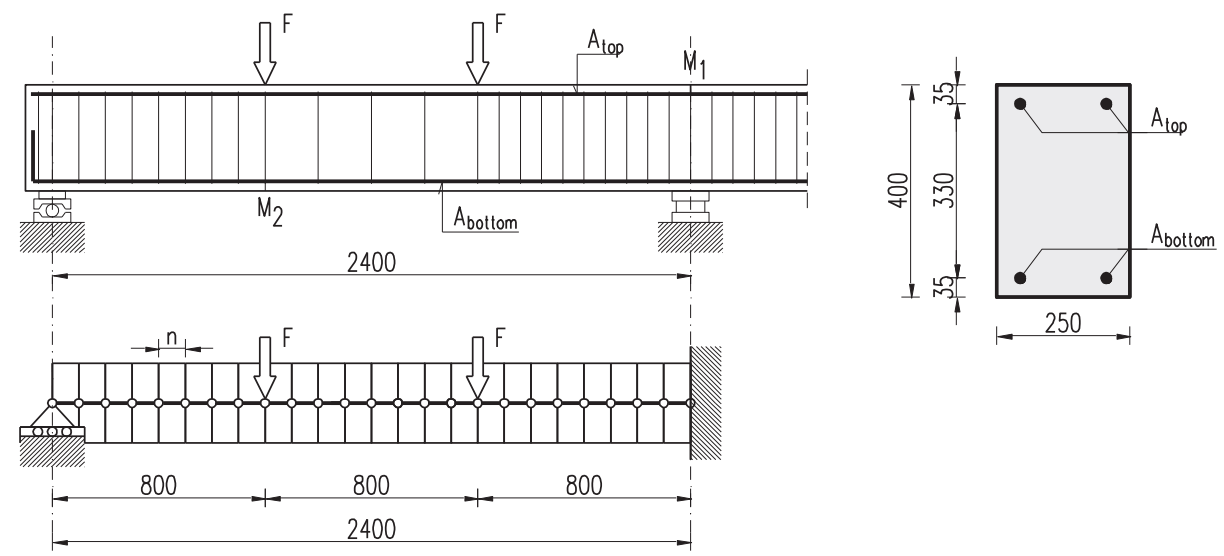

Fig. 8. Beam geometry and the FEM discretization. Source: own study

Numerical analysis of the beams was conducted in OpenSees, an open-source non-linear finite element method framework. One-dimensional elements, with three degrees of freedom at each end, were used. Bending stiffness in the integration points was calculated based on the sectional moment-curvature relationship.

For analysis, the symmetrical two-span beam with a total width of $480 \mathrm{~cm}$ was selected. The beam was loaded in each span with two concentrated forces at a spacing of $80 \mathrm{~cm}$. The cross-section of the element is $40 \mathrm{~cm}$ high and $25 \mathrm{~cm}$ wide.

Figure 8 shows the beam geometry and the discretization method for FEM analysis. 
Table 1. Summary of the geometrical and material parameters of the beams. Source: own study

\begin{tabular}{|c|c|c|c|c|c|c|c|c|c|c|c|c|c|c|}
\hline \multirow{3}{*}{ Beam } & \multicolumn{3}{|c|}{ Geometry } & \multicolumn{6}{|c|}{ Reinforcement } & \multicolumn{5}{|c|}{ Concrete } \\
\hline & $L_{\text {span }}$ & $h$ & $b$ & $A_{\text {top }}$ & $\rho_{\text {top }}$ & $A_{\text {bottom }}$ & $\rho_{\text {bottom }}$ & $f_{\mathrm{y}}$ & $f_{\mathrm{t}}$ & $f_{\mathrm{c}}=f_{\mathrm{lc}}$ & $\varepsilon_{\mathrm{lcu}}$ & $\varepsilon_{\mathrm{cu}}$ & $E_{\mathrm{lcm}}$ & $E_{\mathrm{cm}}$ \\
\hline & $\mathrm{m}$ & $\mathrm{cm}$ & $\mathrm{cm}$ & - & - & - & - & $\mathrm{MPa}$ & $\mathrm{MPa}$ & $\mathrm{MPa}$ & $\%$ & $\%$ & $\mathrm{GPa}$ & $\mathrm{GPa}$ \\
\hline B1 & \multirow{3}{*}{2.4} & \multirow{3}{*}{40} & \multirow{3}{*}{25} & $2 \# 16$ & 0.0044 & $4 \# 16$ & 0.0088 & \multirow{3}{*}{500} & \multirow{3}{*}{675} & \multirow{3}{*}{30} & \multirow{3}{*}{1.47} & \multirow{3}{*}{3.5} & \multirow{3}{*}{20.5} & \multirow{3}{*}{30.5} \\
\hline B2 & & & & $4 \# 16$ & 0.0088 & $2 \# 16$ & 0.0044 & & & & & & & \\
\hline B3 & & & & $3 \# 20$ & 0.0138 & $2 \# 16$ & 0.0044 & & & & & & & \\
\hline
\end{tabular}

For comparative purposes, calculations were made for beams made of lightweight concrete with a density of $\rho=1800 \mathrm{~kg} / \mathrm{m}^{3}$ as well as normal-weight concrete. Three types of reinforcement layout were assumed for both materials. Table 1 shows a summary of all geometrical and material parameters of the beams.

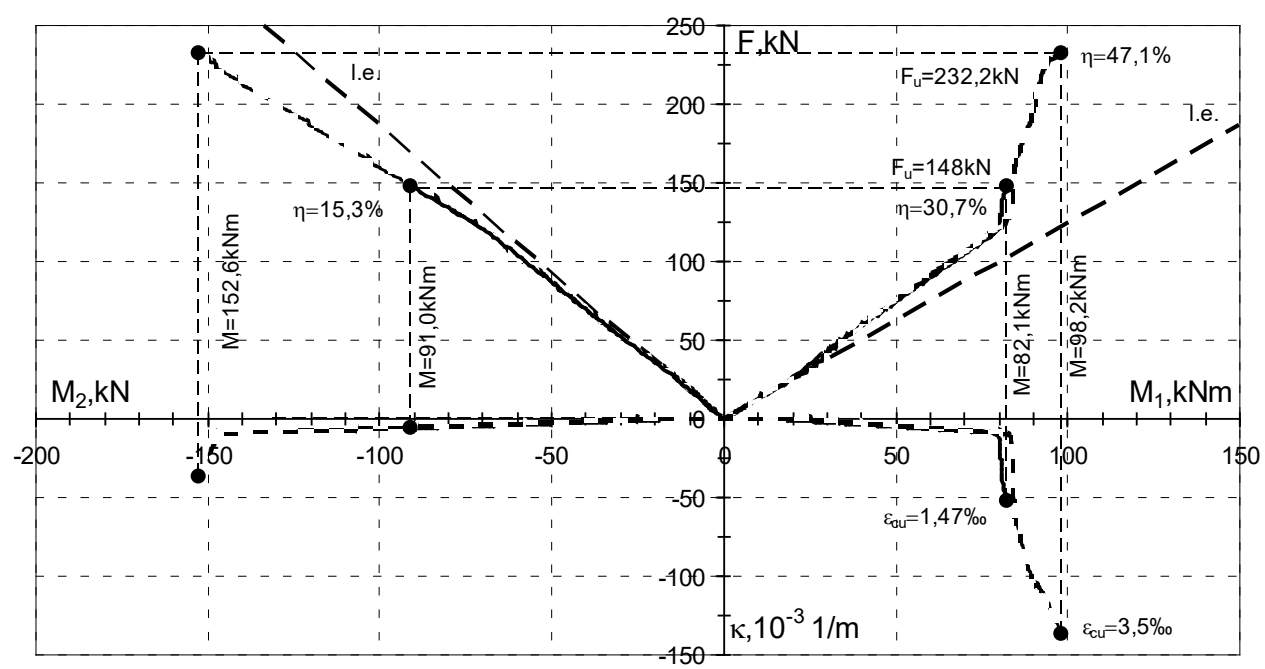

Fig. 9. Calculated redistribution of the moments in the beam B1. Source: own study

Figure 9 shows the calculated impact of the ultimate curvatures on the moment redistribution and load-bearing capacity of the beam B1. The reinforcement arrangement in this beam forces the redistribution of the bending moments from the support to the spans. As we can see, the load capacity of a beam with such a reinforcement system is determined by its ability to deform the support section, both in a beam made of lightweight or normal weight concrete. However, rotation capacity depends on the ultimate compressive strains of the concrete, and those for LWAC with a density of $\rho=1800 \mathrm{~kg} / \mathrm{m}^{3}$ are twice as low as for the normal concrete. At the ultimate curvature of the middle-support cross-section made of lightweight concrete, reinforcement does not yield in the span, and the beam's load capacity is $F_{\mathrm{u}}=148 \mathrm{kN}$. Degree of redistribution at failure is $\eta=30.7 \%$.

In the case of a beam made of normal concrete, for the ultimate curvature in support, the load-bearing capacity of the beam is $F_{\mathrm{u}}=232.2 \mathrm{kN}$, and the reinforcement in the span starts to yield. In this case, the degree of redistribution increases to $47.1 \%$. 
The reinforcement system in B2 type beams is close to elastic - consistent, i.e. that the load capacity of the support section will be achieved simultaneously with the load capacity of the span sections.

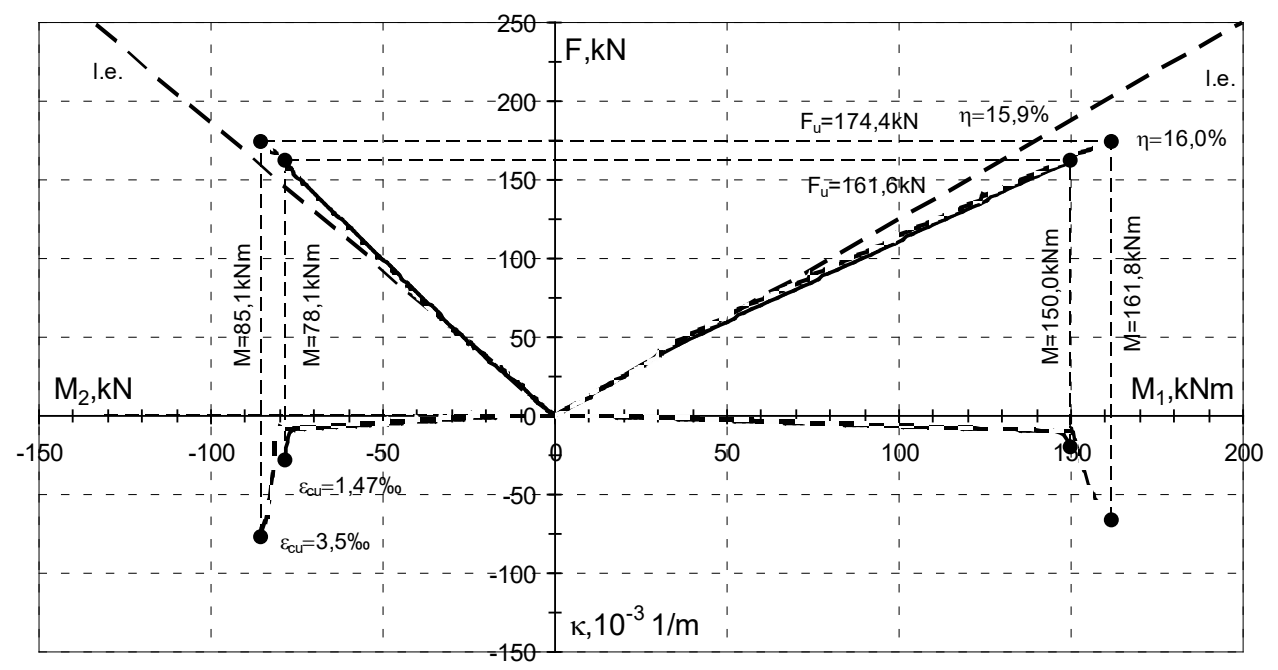

Fig. 10. Calculated redistribution of the forces in the beam B2. Source: own study

In this case (Fig. 10), in both beams, made of lightweight and normal concrete, the reinforcement becomes yielding, both in the span cross-sections and in the middle support section. The differences between the load-bearing capacities are no longer as large as in the case of the B1 beam, and they are respectively $F_{\mathrm{u}}=161.6 \mathrm{kN}$ for a beam made of lightweight concrete, and $F_{\mathrm{u}}=174.4 \mathrm{kN}$ for a beam made of normal concrete. The levels of moment redistribution are the same, at $\eta=16 \%$.

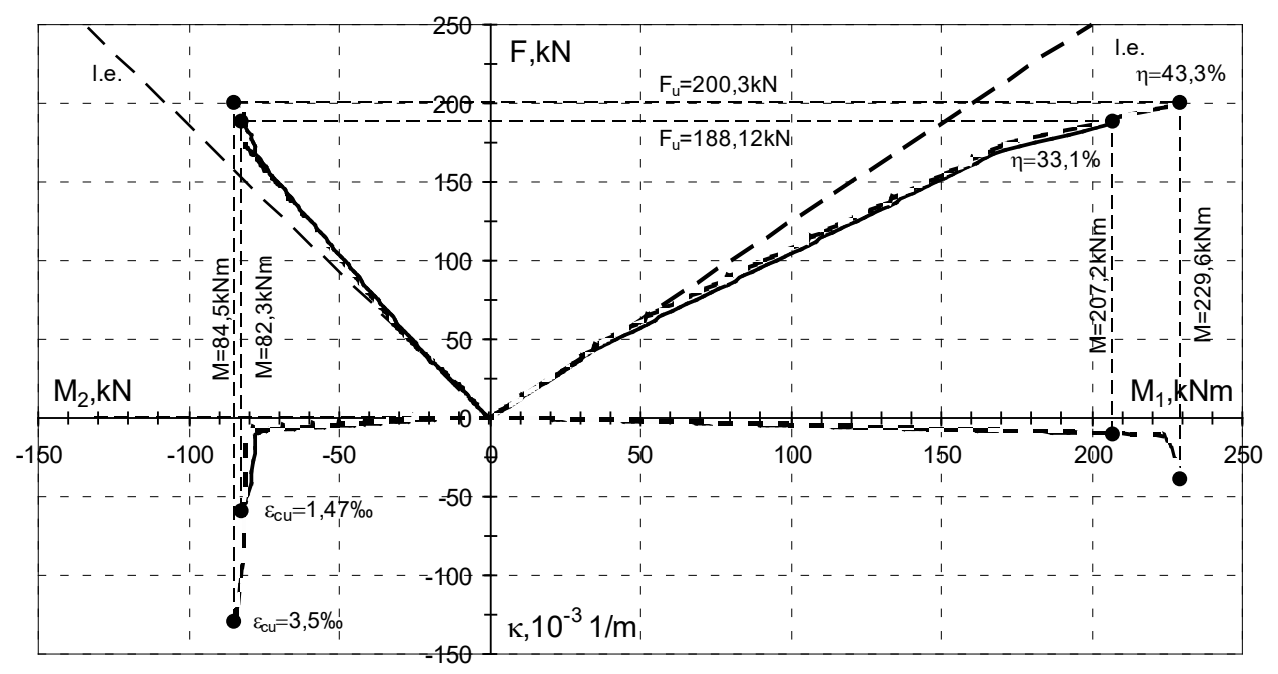

Fig. 11. Calculated redistribution of the forces in the beam B3. Source: own study 
In the last analyzed beam B3, the reinforcement was selected to force a strong redistribution of bending moments from the span to the middle support. Figure 11 shows the calculated impact of the ultimate curvatures on the moment redistribution in this beam.

As can be observed, in this case, the load-bearing capacity of the beam is determined by the ultimate deformability of the cross-sections in the span. For a beam made of normal concrete, the load capacity was $F_{\mathrm{u}}=200.3 \mathrm{kN}$, and for a beam made of LWAC, the limit curvature of cross-sections in the span allowed to achieve the load capacity $F_{\mathrm{u}}=188.1 \mathrm{kN}$. The redistribution degrees were $43.3 \%$ and $33.1 \%$, respectively. The lower deformability of the sections made of LWAC again reduced the redistribution of moments relative to ordinary concrete.

\section{Conclusions}

The following conclusions can be drawn from the computational analysis of sections and beams made of lightweight concrete:

- the ductility of the cross-sections made of lightweight aggregate concrete depends on the density of the concrete and associated with it ultimate compressive strains,

- smaller ultimate compressive strains of the LWAC reduces the plastic branch length of the moment - curvature relationship; this affects the ductility index,

- the lower the density of lightweight concrete, the greater the ductility index of the cross-section,

- tendency mentioned above is more visible for cross-sections with a lower reinforcement ratio,

- the limited deformation capacity of the cross-sections made of lightweight aggregate concrete limits the redistribution of bending moments in the statically indeterminate beams compared to the beams made of normal weight concrete. This is especially visible in the beams reinforced in the non-elastic-consistent way (over-reinforced span or support cross-sections),

- in some extreme cases, the limited rotational capacity if the cross-section in middle support will not allow yielding of the reinforcement in the spans and will strongly reduce the load capacity,

It should be said that normal-weight concrete cannot be freely replaced with LWAC only taking into account compressive strength. When designing reinforced concrete elements made of lightweight aggregate concrete, it is necessary to take into account its limited deformation capabilities and the associated redistribution of internal forces. It is recommended that the rotational capacity of the cross-sections in statically indeterminate elements should be controlled in each case.

\section{References}

[1] European Committee for Standardization. EN 1992-1-1 Eurocode 2: Design of concrete structures Part 1-1: General rules and rules for buildings. CEN, Brussels, 2004.

[2] Øverli J.A., Jensen T.M., "Increasing ductility in heavily reinforced LWAC structures", Engineering Structures, vol. 62-63, (15 March 2014), pp. 11-22.

[3] Carmo N.F., Costa H., Simões T., Lourenço C., Andrade D., "Influence of both concrete strength and transverse confinement on bending behavior of reinforced LWAC beams", Engineering Structures, vol. 48, (March 2013), pp. 329-341. 
[4] Dias-da-Costa D., Carmo R.N.F., Graça-e-Costa R., Valença J., Alfaiate J., "Longitudinal reinforcement ratio in lightweight aggregate concrete beams", Engineering Structures, vol. 81, (15 December 2014), pp. 219-229.

[5] Øverli Jan A., "Towards a better understanding of the ultimate behaviour of LWAC in compression and bending", Engineering Structures, vol. 151, (15 November 2017), pp. 821-838. https://doi. org/10.1016/j.engstruct.2017.08.063

[6] Liu, X., Wu, T., \& Liu, Y., „Stress-strain relationship for plain and fibre-reinforced lightweight aggregate concrete", Construction and Building Materials, vol. 225, 2019, pp. 256-272. https:// doi.org/10.1016/j.conbuildmat.2019.07.135

[7] Naaman A.E., Jeong S.M., "Structural ductility of concrete beams prestressed with FRP tendons", in 2nd Int. RILEM Symp. (FRPRXS-2), Non-Metric (FRP) Reinforcement for Concrete Structures. RILEM, Bagneux, France, 1995, pp. 379-386.

[8] Czkwianianc A., Kamińska M.E., „Metoda nieliniowej analizy żelbetowych elementów prętowych”, Studia z zakresu inżynierii, nr 36 (Institute of Fundamental Technological Research Polish Academy of Sciences, Warsaw, Poland, 1993).

[9] Mander J.B., Chang G., "Seismic energy based fatigue damage analysis of bridge columns: Part I - evaluation of seismic capacity”, Technical Report 94-0006, NCEER, 1994.

[10] Maekawa K., Dhakal P.R., "Path-dependent cyclic stress-strain relationship of reinforcing bar including buckling”, Engineering Structures, vol. 24, 2002, pp. 1383-1396. https://doi.org/10.1016/ S0141-0296(02)00080-9

[11] The Open System for Earthquake Engineering Simulation Manual, Berkeley University of California, Available: https://opensees.berkeley.edu/wiki/index.php/OpenSees_User [Accessed: 01 February 2020] 
